\title{
RIMA DE VALLBONA: ENTRE LA PERMANENCIA Y EL EXILIO
}

\author{
María Amoretti.
}

\begin{abstract}
The literary production of writers in exile is conditioned by the dynamics of the contrary forces of acceptance and rejection of contexts and identities. However, each individual writer finds his own particular manner of resolving this disjunction.

In this article I examine the case of Costa Rican author Rima Vallbona, all of whose works have been produced outside Costa Rica, and propose a hypothesis regarding the way she resolves the expatriate/ impatriate disjunction.
\end{abstract}

Costa Rica no es un país de emigraciones. Más bien se ha caracterizado por ser un receptor de inmigrantes latinoamericanos, por lo tanto diríamos que se trata de un país de inmigraciones. Este fenómeno se atribuye el hecho de que goza de un cierto renombre por un clima político de estabilidad y tolerancia, no en vano se le conoce como una de las democracias más antiguas del continente. Ello hace que haya servido de catalizador para poblaciones o comunidades en conflicto en el resto del continente. Bajo su bandera han encontrado amparo cantidad de chilenos, argentinos y ahora nicaragüenses, salvadoreños y panameños, de toda creencia y profesión política.

Lejos de considerar negativa esta apertura del país, los diferentes grupos migratorios han ofrecido a Costa Rica aportes culturales considerables en el teatro, en la literatura en general, en la artesanía, en la educación, etc. En cuanto a nuestro pequeño récord emigratorio, la última oleada considerable, nunca por su cantidad sino por la calidad de la gente nuestra que abandonó el país, se dio en la década de los cuarenta, cuando por razón de la profunda crisis política del momento -crisis que culminó en una revolución- un grupo de importantes intelectuales tuvo que dejar el país. Entre ellos dos de nuestras más insignes escritoras: Carmen Lyra y Eunice Odio.

El exilio en Costa Rica es normalmente voluntario, si por ello entendemos que no emana de una constricción oficial o gubernamental. Pero no lo sería si consideramos que ese exilio aparece como la única alternativa que deja la coyuntura para poder aspirar a mejores condiciones de vida, en algunos casos, y horizontes de autorealización más amplios, en otros casos. El exilio en Costa Rica no es de tipo político, sino mas bien causado por la pobreza. Y esta es una dif $\rho$ ncia bastante importante entre el caso de nuest país y el de otras naciones de América.

Hablar de migraciones es hablar de enfrentamientos y transformaciones en los hábitos y las costumbres, es hablar de cambios en el género de vida y experimentar la sensación de ser un otro, un marginal y, por tanto, iniciar un proceso de crisis de identidad que obliga a un autoanálisis y a un examen de los contextos abandonados, mirados ahora desde otras perspectivas, impuestas por la distancia y por los traumas de la otredad experimentados en el nuevo contexto.

Sc plantea la disyuntiva hamletiana del ser o no ser, pero leíble también como estar y no estar. De ahí que toda tentativa de definir el objeto marginal se haga en referencia a la metáfora del campo de gravitación: el estatuto de objeto marginal depende de una red de fuerzas contrarias de atracción y repulsión, de aceptación y rechazo.

$\mathrm{La}$ forma en que cada escritor resuelve esta dinámica es muy particular, mi interés en este artículo es arriesgar una hipótesis que defina el modo en que la escritora costarricense Rima de Vallbona resuelve su disyuntiva. El propósito de este trabajo no es, pues, explicar la totalidad de su obra, sino tan sólo intentar una aprehensión o aproximación de ella a partir de su libro Mujeres y agonías y dentro de la perspectiva de su condición de escritora emigrada.

Toda la obra de Rima Vallbona es producida fuera de Costa Rica, pero toda ella es profundamente costarricense: lenguaje, ambientación y personajes. No obstante, los temas, si bien arrancan de coyuntu- 
ras también muy nuestras, tienen un interés que escapa a nuestras fronteras nacionales, como se verá más adelante.

He aquí un rápido recuento de su producción:

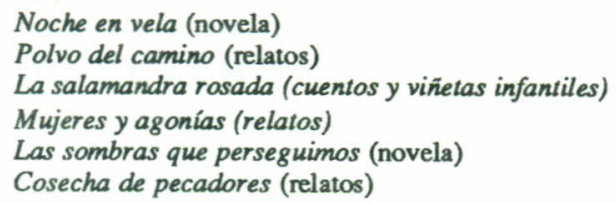

Justo este año cumple veinte años de haber iniciado su carrera como escritora y cuenta ya a su haber con una lista impresionante de premios y reconocimientos muy prestigiosos.

Además de escritora es una académica de igual calidad y reconocimientos, a la que las letras del país le deben aportes tan valiosos en la historia de la literatura nacional como sus libros Yolanda Oreamuno y La obra en prosa de Eunice Odio. Estos dos ensayos recogen obra dispersa y hasta entonces perdida de dos escritoras muy relevantes que también produjeron en condición de emigradas, (en Méjico, las dos), para devolverles el justo reconocimiento que su calidad merece.

Como se deduce del recuento de su producción, Rima Vallbona es una narradora. Su obra es totalmente en prosa, pero con un ritmo interno que amalgama una exquisita tonalidad diegética con una inquietante territorialización lírica que le dan a sus relatos un interés del que es muy difícil escapar.

El tema del exilio presenta en la obra de esta escritora dos facetas harto interesantes: una es la de la búsqueda de la identidad (yo y los otros); otra es la de la relación entre la escritora, su obra y el país de origen. Hay que tener presente que el exilio es sólo una tópica dentro de la semiótica de la marginalidad, por lo tanto el tema del exilio va a leerse como un fenómeno de marginalidad en ambas facetas.

Desde la propia confesión del título, título fidedigno no impostor o pérfido, el texto se inscribe dentro de la problemática de la liberación femenina. Por eso, los relatos que dentro del texto definen esta preocupación presentan un universo que se modela a partir de una conciencia femenina. Son relatos que, aunque narrados a veces en tercera persona, están fuertemente focalizados desde una conciencia femenina o desde la conciencia del hijo que describe a su madre desde su condición de mujer. Esa conciencia femenina mira al mundo desde el borde, el margen de su zona sagrada, íntima, desalienada, pero desde cuya hendija también se escucha el grito angustiado de no encontrar más allá de esa frontera el modo de ser ella misma: su identidad es prisionera de su propia intimidad; más allá de ella, se diluye entre las cosas y es sólo una cosa más entre ellas:

“Quiero ver más allá de las cosas, por lo menos el espacio oscuro de mi interior" (1).

"Sepultada dentro de mí misma, ha llegado el momento de la verdad..."

Por un lado el monstruo de las cosas, creciente, invadiente; por otro, el único refugio posible, "mi espacio interior"; aquel estrecho, devorador; éste amplio, protector. Sin embargo, aún ese espacio interior se convierte en una profundidad silenciosa e infinita y en una frialdad metálica que es sinónimo de sepultura.

En este sentido la búsqueda descrita por el texto es una búsqueda degradada, previamente destinada al fracaso, ya que la identidad sólo es posible en la soledad, en la individualidad, optar por ella es renunciar a la otra condición humana, la de la colectividad. Por eso embarga su obra una especie de sentido trágico pues la búsqueda de sí mismo termina convirtiéndose en un estado de exilio obligatorio. Por eso en Parábola del edén imposible, es el mito de Sísifo el código de transformación del relato y el paraíso alcanzado se transmuta en un nuevo infierno.

En este sentido nada más claro que la función que desempeña el tema de la regresión al estado fetal en el cuento "El monstruo de las cosas".

\footnotetext{
“...la primera agua cálida y espesa que me abrigaba con un abrazo de ala protectora de la que no quería salir nunca, pero me sacaron y entonces hubo las cosas, las voces, los gritos, los ruidos, y ese sentirse perdida entre tanta chatarra".
}

El nacimiento es pues un exilio, un destierro, y la vida exterior una chatarra, un conjunto estéril de cosas inservibles. En ese destierro, el interior, la intimidad hacen las veces de vientre, de útero materno, de ahí que la interioridad, el espacio interior, es el sustituto del edén perdido. Ese es el sentido del mot-valise "interior-vientre".

El sentido trágico de la existencia reside en esta condena que la define, la condena a la marginalidad, al exilio, el paso de lo interior a lo exterior, de lo inclusivo a lo exclusivo, de lo intrínseco a lo extrínseco, de lo auténtico a lo alienante.

Entendida la alienación como un límite a la libertad individual, habrá alienación cada vez que se niegue o imposibilite la subjetividad del individuo. En el texto en estudio esta limitación se encuentra 
investida en la imagen del encierro y la oscuridad. Toda aspiración libertaria, por lo demás es punible $y^{\prime}$ culpabilizante, de ahí que se plantee en términos de pecado o delito.

El infierno, como ya se vio, es esa realidad constrictora y el paraíso la dimensión del sueño, de lo imaginario y de la fantasía, pero mundo solitario al fin, mundo autista del yo en su espacio interior.

Para simplificar e intentar con mayor rapidez una aprehensión global de las formas en que se transmutan los significados en el texto a partir de ciertos contenidos nucleares, vamos a señalar a continuación las matrices que hemos reconocido en el discurso de esta autora, a partir de las cuales se engendran diferentes estructuras pero pertenecientes todas a un mismo conjunto.

\section{La creación del mundo.}

El paraíso. Su presencia se logra a veces también por polarización, de modo que el opuesto complementario es parte de su campo nocional, el infierno.

Adán. Su función negativiza la secuencia que le da origen. Adán es elemento constitutivo de la secuencia de la creación del mundo, es la afirmación del origen de las cosas y la relación con Dios, el Supremo Creador. Pero aquí Adán es el anagrama de la nada, parte de una nueva secuencia, la del descrecimiento, la de la negación de Dios.
El pecado. Por similitud analógica, se ligan a él otros significantes: fruta prohibida, árbol de la felicidad; y por polarización, la inocencia y la pureza.

La culpa. Como se comprenderá, es un significante que se corresponde con el anterior, lo mismo que con el siguiente.

El perdón.

Si tomamos esa lista de títulos, trece en total, que constituyen el libro de Mujeres y Agonías, y los analizamos desde el punto de vista de sus protagonistas, tendríamos dos grandes grupos mayoritarios:

\section{I- Mujeres.}

Penélope en sus bodas de plata.

Parábola del edén imposible.

El monstruo de las cosas.

Bajo pena de muerte.

\section{II- Niños}

Oíd Adán es sal.

El juego de los grandes.

Día de tinieblas.

El arcángel del perdón.

El árbol del chumico.

En el reino de la basura.

Un tercer grupo, aparte y minoritario, lo formarían los relatos titulados:

Nos atreveríamos a afirmar, después de haber examinado cuidadosamente el texto, que estas lexías constituyen el conjunto o tópica mayor a partir de la cual se

engendran casi todos los relatos del texto. Así se nos presentaría su modo de relación:

\begin{tabular}{|c|c|c|c|c|c|c|}
\hline \multirow[b]{2}{*}{ Relatos } & \multicolumn{5}{|c|}{$\begin{array}{l}\text { Lexías } \\
\text { recurrentes }\end{array}$} & \multirow[b]{2}{*}{ El perdón } \\
\hline & $\begin{array}{l}\text { La creacion. } \\
\text { El principio }\end{array}$ & $\begin{array}{l}\text { El paraíso } \\
\text { El infiemo }\end{array}$ & $\begin{array}{l}\text { Adán } \\
\text { La nada } \\
\text { La soledad }\end{array}$ & El pecado & La culpa & \\
\hline Penelópe... & & $\mathrm{X}$ & & $\mathrm{X}$ & & \\
\hline Parébola.. & $\mathrm{X}$ & $\mathrm{X}$ & & $\mathrm{X}$. & & \\
\hline El impostor... & & & & & $\mathrm{X}$ & \\
\hline Beto y... & & $\mathrm{X}$ & $\mathrm{X}$ & & & \\
\hline El monstruo... & $\mathrm{X}$ & $X$ & & & & \\
\hline El juego... & $\mathrm{X}$ & $\mathrm{X}$ & & $X$ & $\mathrm{X}$ & \\
\hline Oíd... & & $\mathrm{X}$ & $\mathrm{X}$ & $\mathrm{X}$ & $\mathrm{X}$ & \\
\hline Bajo pena... & & $\mathrm{X}$ & & $\mathbf{X}$ & $\mathrm{X}$ & $\mathrm{X}$ \\
\hline El árbol del.. & & & $X$ & & $\mathrm{X}$. & \\
\hline El arcángel... & & $X$ & & $X$ & $\mathrm{X}$ & $\mathrm{X}$ \\
\hline Día de... & & & & & $\mathbf{X}$ & \\
\hline En el reino... & & & $X$ & & $\mathbf{X}$ & $\mathrm{X}$ \\
\hline Lo imconparab & ble... & & $\mathrm{X}$ & $\mathrm{X}$ & $\mathbf{X}$ & \\
\hline
\end{tabular}


III-

El impostor.

Beto y Betina.

Lo inconfesable.

De este último grupo nos ocuparemos al final, pero es necesario anticipar que no quedan fuera de la comprensión global que estamos intentando de la obra como un todo.

Los dos grupos mayoritarios, cuentos de mujeres y cuentos de niños constituyen el relato de dos sujetos marginales, de manera que mantienen una estrecha relación que se acrecienta, como se pudo observar en el gráfico, por el hecho de que los relatos de un grupo y de otro están construidos a partir de las mismas figuras matriciales: culpa, pecado, soledad, etc.

Los relatos de mujeres plantean un conflicto de identidad que es culpabilizante porque representa una transgresión:

"Ella no puede, -no debe- romper el rito monótono del picadillo, el tamal, la yuca...las penas del infierno... que siga tejiendo junto a la ventana".

(Penélope...)

"Ella presintió la voz ubicua que decía no, pero ya estaba cansada de tanto no; su vida arrastraba una sarta de no-se-puede, no-sehace, no-se-tiene, no-no-no-no".

(Parábola del Edén imposible).

Lineas aparte merece un relato excepcionalmente hermoso titulado "Bajo pena de muerte". Representa una nota excepcional porque su propósito medular es resaltar una figura femenina extraordinaria, elevada a la calidad de héroe por su coraje y caridad. Sin embargo, afloran en él las relaciones esenciales que definen los otros relatos de mujeres, tales como la identificación entre cosas y alienación:

\footnotetext{
"Ella, que se había confundido siempre con las cosas por su pequeñez, ¿había crecido durante la noche, pues ahora él tenía que empinarse mucho para mirarla a los ojos?".
}

Narrado desde el foco de Pablo, el único hijo de la viuda, éste siente que la apocalipsis que enfrenta no podia ser otra cosa que castigo de Dios: "¿Qué crimen has cometido, Pablo? Mírate en el espejo de tu conciencia y responde, Pablo, ¿qué crimen has cometido?".

He aquí de nuevo el tema de la culpa.
En el caso de los relatos de ninos, el tema general es la infancia de cara al pecado y a la culpa. Así, en Oíd Adán es sal, el descreimiento de los niños victimiza a su querido perro por ser su nombre genérico el anagrama tabú del nombre de Dios. EnEl juego de los grandes, la culpa se ilustra gráficamente con la caída del pene del protagonista y narrador en el inodoro y su frustrado intento por rescatarlo.

El relato En el reino de la basura, se refiere a la radical marginalidad de una niña, que abandonada de todos, pero muy especialmente de los otros niños, aparece muerta en medio de los detritus de la basura, con la que la habían identificado siempre. No obstante, ante ese tétrico cuadro final, los otros niños parecen ignorar su responsabilidad en el evento, es decir, evitan a toda costa la autoculpación.

En Día de tinieblas, además del tópico de la oscuridad, tan recurrente en los demás relatos también, el niño protagonista experimenta una crisis de identidad que supera justamente para evitar la muerte de su ternerito Lucero, de la que sería culpable si continuara con un cambio de identidad que le resultaba tan interesante como ventajoso.

En El arcángel del perdón, los robos de la niña golosa materializan un Demonio-culpa que provoca el caos en la ciudad y la niña debe obtener el perdón de la Virgen del Camino.

En El árbol del chumico se da una interesante polaridad con otro árbol, elárbol de los cincos que no crece ni da frutos. Pareciera que Menchita, la niña buena pero rica, (el relato así plantea la situación, es decir, no encuentra otra culpa más que esa), debe pagar la culpa de tener dinero no teniendo acceso al círculo mágico de la felicidad de los pobres.

El tercer grupo, el de los relatos inclasificados, se aglutinan a la problemática general del texto cada uno en una forma que le es propia. En Beto y Betina tenemos el problema de la identidad sexual y por tanto el tema de la completitud y la carencia.

En El impostor, es nuevamente el problema de la identidad, sólo que artísticamente tratado en un juego de temporalidades y espacios diversos, y en un juego de fantasía y realidad, de vigilia y sueño.

Lo inconfesable presenta el conflicto de un cura acusado de heterodoxia en la práctica confesionaria. La confesión, espacio de la culpa y el perdón por antonomasia. El pecado de la carne en dos grupos humanos de gran represión en este aspecto: la mujer y el cura.

No cabe duda que las imágenes matriciales del texto refieren al discurso bíblico y que los conflictos de culpa se derivan de una noción de pecado estre- 
chamente ligada a la religión al igual que de una comprensión de la vida como continua reparación de pecados propios y ajenos.

El pecado es una desviación, por eso al pecador se le ha representado como la oveja descarriada. Es una desviación del centro, que es Dios. El centro es una noción de prestigio en cualquier registro que se la ubique: Dios, la normalidad, lo aceptable. Cualquier desviación es pecado, anormalidad o rechazo. Tal es el prestigio del centro, que ha alcanzado la condición de sagrado.

En el registro antropomórfico, el centro es el ombligo, de ahí que cuando se quiere hablar de un lugar como el centro del mundo, se describe como el ombligo del mundo. En el cuerpo humano, el ombligo es, pues, el centro. Pero el ombligo arrastra nuevas redes de relaciones con otro tipo de secuencias como son las del origen y de la creación. Cuando hablamos del ombligo nos referimos a las etapas embrionarias del ser, buscar ese centro-ombligo es buscar el centro de uno mismo, la zona prestigiada del ser, la zona sagrada, el yo, la identidad.

El camino que lleva al centro es duro, difícil. Así, el camino del que busca el yo. Por eso el camino que conduce hacia el centro del ser, está definido por el título de la obra como una agonía, una lucha, contra lo cotidiano, lo repetido, contra la linealidad y contra el tiempo.

Ese camino constituye un rito de paso entre lo profano y lo sagrado, entre lo efímero y lo eterno, entre lo ilusorio y lo real.

El acceso al centro equivale a una consagración, a una iniciación por eso, en el relato de Penélope en sus bodas de plata, se rodea de todo un ritual: la fiesta, los veinticinco años, el discurso, el brindis, toda la ceremonia para anunciar la liberación del yo, la vuelta al centro.

Así, los relatos de Rima de Vallbona son una épica del yo que tiene su propio sagrado lenguaje, nacido de un esfuerzo consciente por trabajar con el material sonoro y gráfico de las palabras y darle a su narrativa una importante energía connotativa que combina el temple anímico de la prosa con la exuberante fantasía de la lírica.

Si ahora trasladamos este sistema significante que acabamos de examinar en el plano del enunciado, al puro nivel de la enunciación, de modo que explique el porqué se ha generado o se ha operado su escogimiento, tendríamos la siguiente situación:

La autora es una emigrada, pero a diferencia de otros casos costarricenses, las condiciones objetivas del exilio no son tema de su producción literaria.

Como dijimos al inicio de este trabajo, la problemática del exilio conlleva dentro de sí, siempre un cuestionamiento del yo y su circunstancia, por lo tanto un planteamiento del tema de identidad, tópico que aparece de forma relevante en las obras de Rima de Vallbona. Por ello podríamos agregar que la producción de esta autora destaca los aspectos subjetivos, más que las condiciones objetivas de la emigración.

Entre el exilio y la permanencia, Rima de Vallbona ha resuelto por permanecer literariamente en su país de origen, como un modo también de evitar una sensación culpabilizante, pues de un modo o de otro, consciente o inconscientemente, el haber dejado su terruño, el haberse automarginado alejándose de su propio centro circunstancial originario, es visualizado como una falta.

Si seguimos al gran filósofo británico, John L. Austin, la permanencia literaria de Rima de Vallbona es una excusa, una justificación, es decir algo así como: "lo hice, pero sólo en cierto modo". "Me fui, pero sólo en cierto modo".

Efectivamente, la preocupación, el grado de vinculación de Rima de Vallbona con su país es siempre constante y muy leal. Su producción es una ofrenda de afecto de gran valía para la cultura nacional y este artículo quiere ser un modo de decirle muchas gracias por proyectar nuestro país no sólo.en los Estados Unidos, sino a través de toda Américaen su doble condición de escritora y académica.

\section{NOTAS}

(1) Todas las citas del texto Mujeres y Agonías provienen de su primera edición. Houston, Texas: Arte Público Press. 1986.

\section{BIBLIOGRAFIA}

Vallbona, Rima (de). Mujeres y agonias. Houston, Texas: Arte Público Press. 1986. 
